\title{
15-Deoxy- $\triangle^{12,14}$-ProstaglandinJ2 Regulates Dedifferentiation through Peroxisome Proliferator-Activated Receptor- $\gamma$-Dependent Pathway but Not COX-2 Expression in Articular Chondrocytes
}

\begin{abstract}
Peroxisome proliferator-activated receptors- $\gamma$ (PPAR- $\gamma$ ) is critical for phenotype determination at early differentiation stages of mesenchymal cells, whereas its physiological role is unclear. Therefore, we investigated the role of 15-deoxy- $\Delta^{12,14}$-prostaglandinJ2 (15d-PGJ2), the natural receptor ligand for PPAR- $\gamma$, on dedifferentiation and inflammatory responses, such as COX-2 expression and $\mathrm{PGE} 2$ production, in articular chondrocytes. Our data indicate that the 15d-PGJ2 caused a loss of differentiated chondrocyte phenotype as demonstrated by inhibition of type II collagen and proteoglycan synthesis. 15d-PGJ2 also induced COX-2 expression and PGE production. The 15d-PGJ2-induced dedifferentiation effect seems to be dependent on PPAR- $\gamma$ activation, as the PPRE luciferase activity increased and PPAR- $\gamma$ antagonist, BADGE, abolished type II collagen expression. However, BADGE did not block 15d-PGJ2-induced COX-2 expression. Collectively, our findings suggest that PPAR- $\gamma$-dependent and -independent mechanisms of 15d-PGJ2-induced dedifferentiation and inflammatory responses in articular chondrocytes, respectively. Additionally, these data suggest that targeted modulation of the PPAR- $\gamma$ pathway may offer a novel approach for therapeutic inhibition of joint tissue degradation.
\end{abstract}

Key Words : Cell Differentiation; Cyclooxygenase 2; PPAR Gamma; Chondrocytes

\author{
Ji-Hye Lee', Seon-Mi Yu', \\ Eun-Kyung Yoon, Won-Kil Lee, \\ Jae-Chang Jung*, Song-Ja Kim
}

Department of Biological Sciences, College of Natural Sciences, Kongju National University, Gongju; Department of Biology*, College of Natural Sciences, Kyungpook National University, Daegu, Korea

'These authors contributed equally to this work.

Received : 6 December 2006 Accepted : 24 January 2007

Address for correspondence

Song-Ja Kim, Ph.D.

Department of Biological Sciences, Kongju National University, 182 Shinkwan-dong, Gongju, Korea Tel : +82.41-850-8507, Fax : +82.41-850-8479 E-mail : ksj85@kongju.ac.kr

*This work was supported by Korea Research Foundation Grant funded by the Korean Government (MOEHRD, Basic Research Promotion Fund) (KRF2005-202-100654), Rheumatoid Research Center Program (KOSEF Grant R11-2002-098-05001-0).

\section{INTRODUCTION}

Peroxisome proliferator-activated receptors (PPARs) are members of the ligand-activated nuclear hormone receptor superfamily (1). Three PPAR isoforms $(\alpha, \gamma$ and $\delta)$ differ in their tissue distribution and ligand specificity (1). PPAR- $\alpha$ is present in heart, kidney, and liver and appears to primarily regulate genes involved in lipid and lipoprotein metabolism $(1,2)$, whereas PPAR- $\delta$ expression is ubiquitous $(3,4)$ and its physiological role is unclear (5). PPAR- $\gamma$ is expressed predominantly in adipose tissue, with lower levels in muscle and liver $(6,7)$. Although the physiological role of PPAR- $\gamma$ has not been clearly determined, it appears to be an important transcriptional regulator of genes involved in glucose and lipid metabolism. It was originally characterized as a regulator of adipocyte differentiation and lipid metabolism. PPAR$\gamma$ was also shown to be expressed in other cell types, including T lympocytes and chondrocytes (8-10).

PPAR- $\gamma$ can heterodimerize with at least one other member of the steroid receptor superfamily, retinoid acid receptor (RXR) (11). Ligand-activation of the PPAR- $\gamma:$ RXR heterodimer has been shown to modulate the transcription of genes involved in lipid metabolism, inflammation, and cell differentiation (12). Recent evidence also shows that the natural receptor ligand for PPAR- $\gamma, 15$ d-PGJ2 (13), and synthetic antidiabetic thiazolidinedione drugs (e.g. BRL49653, rosiglitazone [Rtz] and ciglitizone), inhibit macrophage and monocyte activation (14) and suppress tumor cell growth (15). Specific ligands for the PPAR- $\gamma$ and RXR have been shown to act synergistically to induce terminal differentiation of human liposarcoma cells (16) in vitro and to enhance insulin sensitivity in diabetic animals (17).

To maintain cartilage homeostasis, articular chondrocytes synthesize cartilage-specific extracellular matrix molecules, including type II collagen and sulfated proteoglycans (18). This homeostasis is lost in cartilage diseases such as rheumatoid arthritis (RA) and osteoarthritis (OA), eventually leading to cartilage destruction. Cartilage destruction involves a loss of differentiated chondrocyte phenotypes (i.e. dedifferentiation), which is characterized by the cessation of type II collagen expression and onset of fibroblastic type I and type III collagen expression (19). Interleukin- $1 \beta$ (IL- $\beta$ ) and tumor necrosis factor $\alpha$ (TNF $\alpha$ ) have been shown to inhibit the synthesis of cartilage components and to promote their degradation by activating metalloproteinases (20). Concurrently to these effects, they induce the production by chondrocytes 
of inflammatory mediators such as prostaglandins, nitric oxide (NO), and other reactive oxygen species (21). To date most of the drugs marketed as nonsteroidal anti-inflammatory drugs or corticosteroids are unable to prevent cartilage damage (22). Thus, intense investigations are carried out to precise the transduction pathways that impair cartilage homeostasis in order to find new strategies that would be helpful to prevent cartilage destruction.

In this study, we investigated whether 15d-PGJ2, PPAR$\gamma$ activator, may modulate the differentiation and inflammation in rabbit articular chondrocytes. We report here that PPAR- $\gamma$ activation induces dedifferentiation but not inflammation in articular chondrocytes. These results suggest that PPAR- $\gamma$ agonists may provide a new therapeutic approach for RA and OA.

\section{MATERIALS AND METHODS}

\section{Monolayer culture of rabbit articular chondrocytes and experimental culture condition}

Rabbit articular chondrocytes were released from cartilage slices of 2-week-old New Zealand white rabbits by enzymatic digestion. Briefly, cartilage slices were aseptically dissected and then dissociated enzymatically for $6 \mathrm{hr}$ in $0.2 \%$ collagenase type II (381 U/mg solid, Sigma Louis, MO, U.S.A.) in phosphate-buffered saline, and then individual cells were obtained by collecting the supernatant after brief centrifugation. The cells were resuspended in Dulbecco's modified Eagle's medium (DMEM, Gibco-BRL, Gaithersburg, MD, U.S.A.) supplemented with $10 \%$ (v/v) fetal bovine-calf serum, $50 \mu \mathrm{g} / \mathrm{mL}$ streptomycin, and 50 units $/ \mathrm{mL}$ penicillin, after which they were plated on culture dishes at a density of $5 \times$ $10^{4} \mathrm{cells} / \mathrm{cm}^{2}$. The medium was changed every 2 days after seeding, and cells reached confluence in approximately 5 days. Differentiation status of articular chondrocytes was determined by examining the accumulation of sulfated glycosaminoglycan with Alcian blue staining or expression of type II collagen (Chemicon, Temecula, CA, U.S.A.) by immunoblot analysis as described previously (23).

\section{Immunoblot analysis}

Whole cell lysates were prepared by extracting proteins using a buffer containing $50 \mathrm{mM}$ Tris- $\mathrm{HCl}, \mathrm{pH} 7.4,150$ $\mathrm{mM} \mathrm{NaCl}, 1 \%$ Nonidet P- 40 , and $0.1 \%$ sodium dodecylsulfate, supplemented with protease inhibitors $(10 \mu \mathrm{g} / \mathrm{mL}$ leupeptin, $10 \mu \mathrm{g} / \mathrm{mL}$ pepstatin $\mathrm{A}, 10 \mu \mathrm{g} / \mathrm{mL}$ aprotinin and $1 \mathrm{mM}$ of 4-[2-aminoethyl] benzenesulfonyl fluoride) and phosphatase inhibitors $\left(1 \mathrm{mM} \mathrm{NaF}\right.$ and $\left.1 \mathrm{mM} \mathrm{Na}_{3} \mathrm{VO}_{4}\right)$. The proteins were size-fractionated by SDS-polyacrylamide gel electrophoresis and transferred to a nitrocellulose membrane. The nitrocellulose sheet was then blocked with 3\% non-fat dry milk in Tris-buffered saline. COX-2 was detected using antibody purchased from Cayman Chemical (Ann Arbor, MI, U.S.A.). SOX-9, ERK-2, and PPAR- $\gamma$ were detected using antibodies purchased from Santa Cruz Biotech (Santa Cruz, CA, U.S.A.). The bands were visualized using peroxidase-conjugated secondary antibodies and chemiluminescence.

\section{Immunohistochemistry}

Rabbit joint cartilage explants or arthritic cartilage were fixed in $4 \%$ paraformaldehyde in PBS for $24 \mathrm{hr}$ at $4{ }^{\circ} \mathrm{C}$, washed with PBS, dehydrated with graded ethanol, embedded in paraffin, and sectioned at $4-\mu \mathrm{m}$ thickness. The sections were stained by standard procedures using Alcian blue or antibody against type II collagen or COX-2 and visualized by developing with a kit purchased from DAKO (Carpinteria, CA, U.S.A.), following the procedure recommended by the manufacturer.

\section{$\mathrm{PGE}_{2}$ assay}

$\mathrm{PGE}_{2}$ production was determined by measuring the levels of cellular and secreted $\mathrm{PGE}_{2}$ using an assay kit (Amersham Pharmacia Biotech, NJ, U.K.). Briefly, chondrocytes were seeded in standard 96-well microtiter plates at $2 \times 10^{4} \mathrm{cells} /$ well. Following addition of the indicated pharmacological reagents, supernatant was used to quantify the amount of $\mathrm{PGE}_{2}$, according to the manufacturer's protocol. $\mathrm{PGE}_{2}$ levels were calculated against a standard curve of $\mathrm{PGE}_{2}$ and normalized against the amount of genomic DNA.

\section{Transfection and reporter assays}

The reporter construct (3xPPRE-TK-luc/pGL3) used in the transfections contained three copies of the peroxisome proliferator response element (PPRE) site from the aP2 enhancer (ARE7) inserted upstream of a minimal thymidine kinase (TK) promoter in the pGL3 basic luciferase vector and $\mathrm{RXR} \alpha$ cDNA (a gift from Dr. JB, Kim at Seoul National University). Transfection of the reporter vector was performed as described previously (23). Chondrocytes cells were grown in $10 \%$ fetal calf serum/DMEM and co-transfected with various reporter plasmids $(1 \mu \mathrm{g})$ and pCMV $\beta$-galactosidase plasmid $(0.5 \mu \mathrm{g})$ (Clontech, Palo Alto, CA, U.S.A.) using Lipofectamine (Life Technologies, Inc., Grand island, NY, U.S.A.), following the procedure recommended by the manufacturer. The transfected cells were cultured in complete medium for $24 \mathrm{hr}$ and used for further assay. Cells were treated with increasing concentrations $(0-20 \mu \mathrm{M})$ or times $(0-24 \mathrm{hr})$ of $15 \mathrm{~d}-\mathrm{PGJ} 2$. Luciferase and $\beta$-galactosidase activities were determined in all extracts using a Luciferase assay (Promega, Madison, WI, U.S.A.) and Galacto-light system (Tropix, Inc., Bedford, MA, U.S.A.). The activities were corrected for transfection efficiency with $\beta$-gal activity and expressed as fold-induction relative to the level 
in untreated cells. Each assay was performed in triplicate. Data are the mean $+/$ - SD of three separate experiments performed with cells from different animals (**pd 0.01 versus non treated cells).

\section{Reverse transcriptase polymerase chain reaction (RT-PCR)}

Primary culture chondrocytes were treated with $15 \mathrm{~d}-\mathrm{PGJ} 2$. Total RNA was isolated using RNA STAT-60 (Tel-Test B, Inc., Friendswood, TX, U.S.A.) and reverse-transcribed with MoMLV-RT (Invitrogen, California, U.S.A.) as previously described (26). The following primers and conditions were used for PCR in rabbit articular chondrocytes: for type II collagen (370-bp product), 5' -GAC CCC ATG CAG TAC ATG CG-3' (sense) and 5' -AGC CGC CAT TGA TGG TCT CC-3' (antisense) with an annealing temperature of 55 ${ }^{\circ} \mathrm{C}$; for SOX-9 (386-bp product), 5' -GCG CGT GCA GCA CAA GAA GGA CCA CCC GGA TTA CAA GTA C-3' (sense) and 5' -CGA AGG TCT CGA TGT TGG AGA TGA

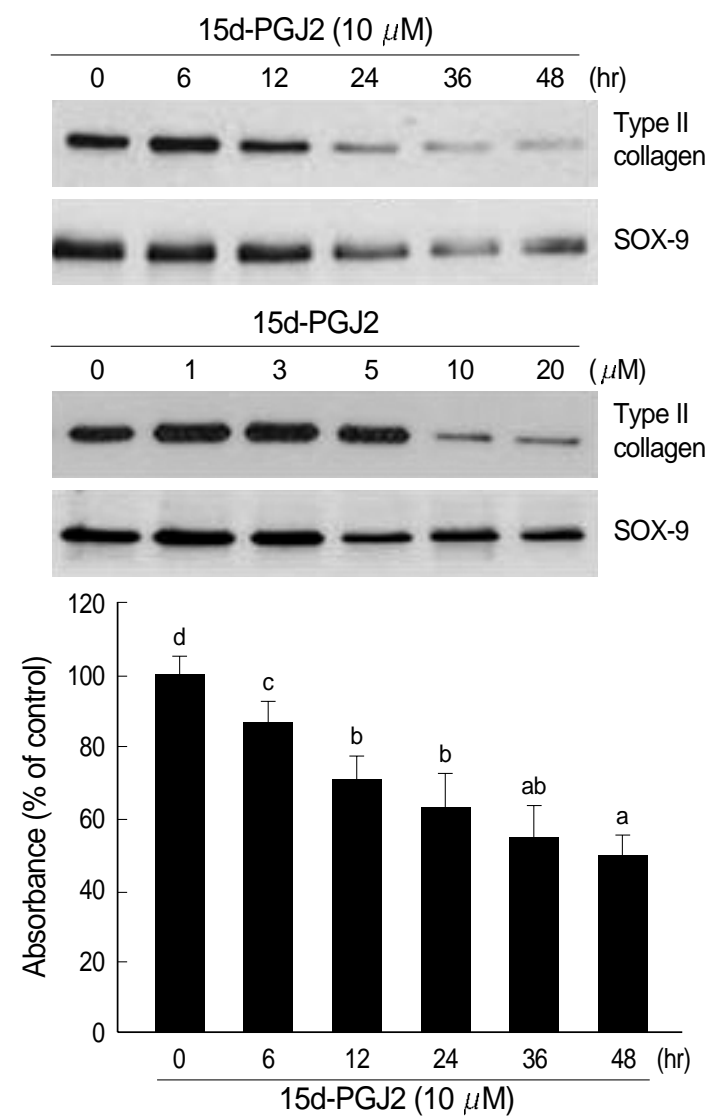

CGT CGC TGC TCA GCT C-3’ (antisense) with an annealing temperature of $62^{\circ} \mathrm{C}$; for COX-2 (298 bp product), $5^{\prime}$ TCA GCC ACG CAG CAA ATC CT-3' (sense) and 5' -GTG ATC TGG ATG TCA GCA CG-3' (antisense) with an annealing temperature of $52^{\circ} \mathrm{C}$ for glyceraldehydes 3-phosphate dehydrogenase (GAPDH; 299-bp products), 5' -TCA CCA TCT TCC AGG AGC GA- 3 ' (sense) and 5' -CAC AAT GCC GAA GTG GTC GT-3' (antisense) with an annealing temperature of $50^{\circ} \mathrm{C}$ The primers for rabbit type II collagen and rabbit SOX-9 were de- signed based on the sequence of human homologs, and sequencing of PCR product showed $89 \%$ and 93\% homology with corresponding human genes.

\section{Data analyses and statistics}

The results are expressed as the means \pm S.E. values calculated from the specified number of determinations. Analysis of variance (ANOVA) was performed to compare individual treatments with their respective control values. The Turkey's honestly significant difference method was employed when
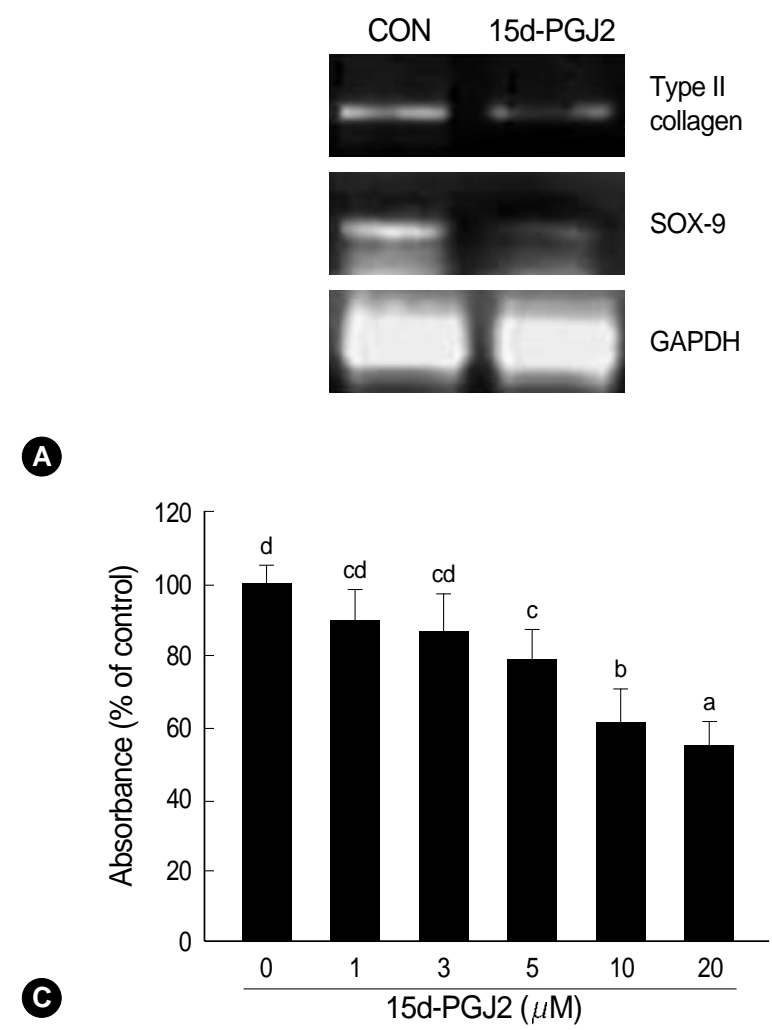

Fig. 1. 15d-PGJ2 causes dedifferentiation of articular chondrocytes. (A) Primary culture chondrocytes were treated with the PPAR- $\gamma$ activator 15d-PGJ2 (10 $\mu \mathrm{M})$ for various time periods (upper panel, A) or with the indicated concentrations of 15d-PGJ2 for $24 \mathrm{hr}$ (lower panel, A). Expression of type II collagen and SOX-9 was detected using immunoblot analysis. (B) Articular chondrocytes were left untreated (con) or were treated with $10 \mu \mathrm{M} 15 \mathrm{~d}-\mathrm{PGJ} 2$ for $24 \mathrm{hr}$, and expression of type II collagen, SOX-9, and GAPDH was determined by RT-PCR. GA$\mathrm{PDH}$ was used as loading controls. (C) and (D) Accumulation of sulfated glycosaminoglycan was quantified by Alcian blue staining. The data represent results of a typical experiment $(A$ and $B$ ) or mean values $\pm S$.D. ( $C$ and $D)$ from at least four independent experiments. The letters on the bar indicate significant differences among means $(n=5)$ at $p=0.05$ using the Turkey's honestly significant difference method. 
making multiple comparisons among means (24).

\section{RESULTS}

\section{5d-PGJ2 induces dedifferentiation in articular chondro- cytes}

To examine the effects of $15 \mathrm{~d}-\mathrm{PGJ} 2$ on articular cartilage chondrocyte differentiation, rabbit articular chondrocytes in primary culture were treated with $10 \mu \mathrm{M} 15 \mathrm{~d}-\mathrm{PGJ} 2$ for 48 hr. Under these experimental conditions 15d-PGJ2 displayed no cytotoxicity, as assessed by the conversion of a tetrazolium compound to its formazan product, as well as trypan blue exclusion (data not shown). 15d-PGJ2 inhibited type II collagen, a marker for differentiation of chondrocytes, and SOX9 expression, a major transcription factor that regulates type II collagen expression, in a dose- and time-dependent manner as determined by immunoblot analysis (Fig. 1A). RTPCR also showed that expression of type II collagen and SOX-

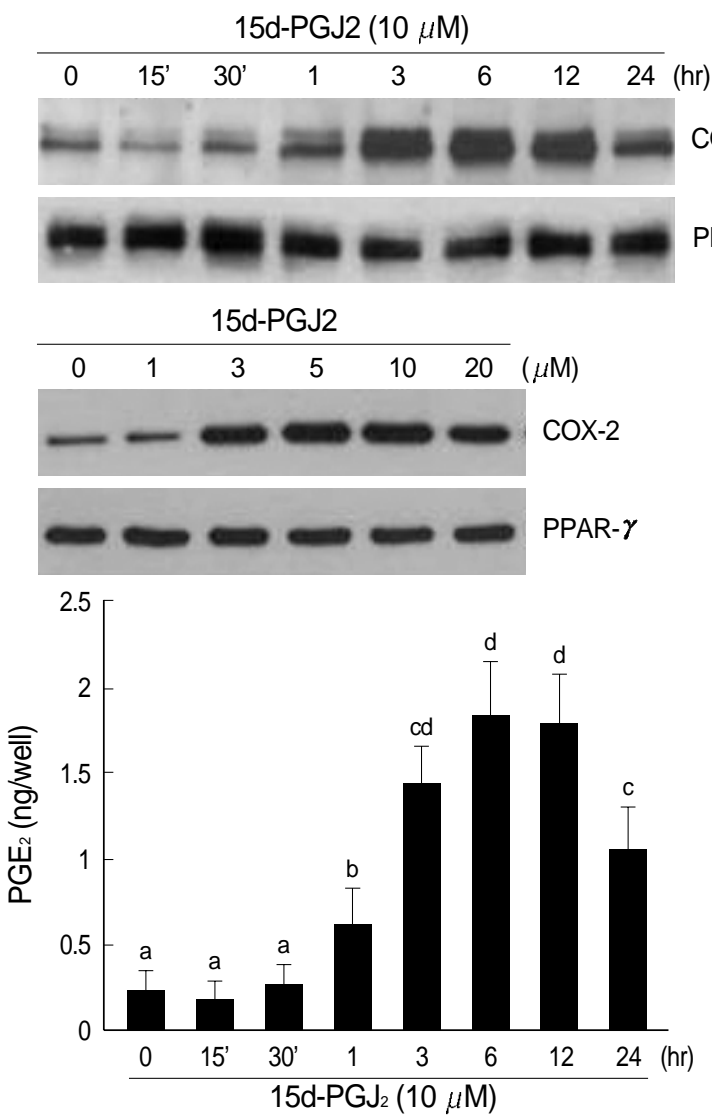

9 was reduced (Fig. 1B). Similarly, 15d-PGJ2 treatment of primary culture cells blocked the accumulation of sulfated proteoglycan in a dose- and time-dependent manner (Fig. $1 \mathrm{C}, \mathrm{D})$. The effects of rosiglitazone, a PPAR- $\gamma$ natural ligand, on dedifferentiation and COX-2 expression in articular chondrocytes showed the same results (data not shown). These results indicate that 15d-PGJ2 induces dedifferentiation of articular chondrocytes in primary culture cells.

\section{5d-PGJ2 increases COX-2 expression and $\mathrm{PGE}_{2}$ production in articular chondrocytes}

The effect of 15d-PGJ2 on COX-2 expression and $\mathrm{PGE}_{2}$ production was investigated using primary culture chondrocytes. In chondrocytes, 15d-PGJ2 increased protein levels of COX-2 in a time- and dose-dependent manner as determined by immunoblot analysis (Fig. 2A). COX-2 expression was increased $1 \mathrm{hr}$ after 15d-PGJ2 treatment, and the levels peaked at 6 hr. 15d-PGJ2 treatment, however, did not affect PPAR$\gamma$ expression levels. 15d-PGJ2 also enhanced COX-2 expres-
COX-2 PPAR- $\gamma$

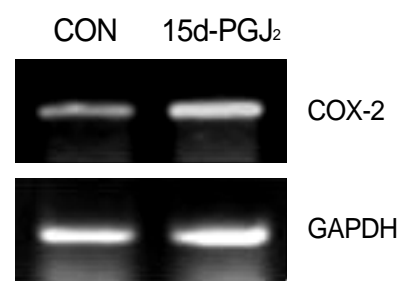

A

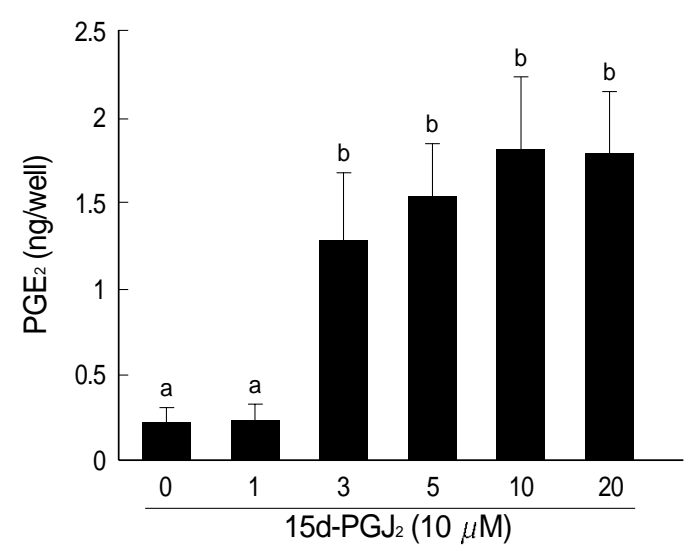

D

Fig. 2. 15d-PGJ2 induces COX-2 expression and PGE 2 production in articular chondrocytes. (A) Primary culture chondrocytes were treated with 15d-PGJ2 (10 $\mu \mathrm{M}$ ) for various time periods (upper panel, A) or with the indicated concentrations of 15d-PGJ2 for $24 \mathrm{hr}$ (lower panel, A). Expression of COX-2 and PPAR- $\gamma$ was detected using immunoblot analysis. (B) Articular chondrocytes were left untreated (con) or were treated with $10 \mu \mathrm{M} 15 \mathrm{~d}-\mathrm{PGJ} 2$ for $24 \mathrm{hr}$, and expression of COX-2 and GAPDH was determined by RT-PCR. GAPDH was used as loading controls. (C) and (D) $\mathrm{PGE}_{2}$ production was measured using an $\mathrm{PGE}_{2}$ assay kit and normalized by determining the amount of total genomic DNA. The data represent results of a typical experiment or mean values \pm S.D. from at least four independent experiments. The letters on the bar indicate significant differences among means $(n=5)$ at $p=0.05$ using the Turkey's honestly significant difference method. 
sion as determined by RT-PCR (Fig. 2B). Consistent with the induction of COX-2 expression, 15d-PGJ2 stimulated $\mathrm{PGE}_{2}$ production in a time- and dose-dependent manner (Fig. 2C, D). The production of $\mathrm{PGE}_{2}$ was determined by using a $\mathrm{PGE}_{2}$ assay kit. $\mathrm{PGE}_{2}$ levels were calculated against a standard curve of $\mathrm{PGE}_{2}$. These data indicate that 15d-PGJ2 not only causes dedifferentiation of articular chondrocytes but also stimulates $\mathrm{COX}-2$ expression and $\mathrm{PGE}_{2}$ production.

\section{5d-PGJ2 causes dedifferentiation and induction of COX-2 expression in cartilage explants}

To examine the effects of 15d-PGJ2 on articular cartilage chondrocyte dedifferentiation and COX-2 expression, cartilage explant cultures were treated with $10 \mu \mathrm{M} 15 \mathrm{~d}-\mathrm{PGJ} 2$ for $24 \mathrm{hr}$, and cartilage-specific matrix molecules were determined. 15d-PGJ2 caused a dramatic loss of type II collagen

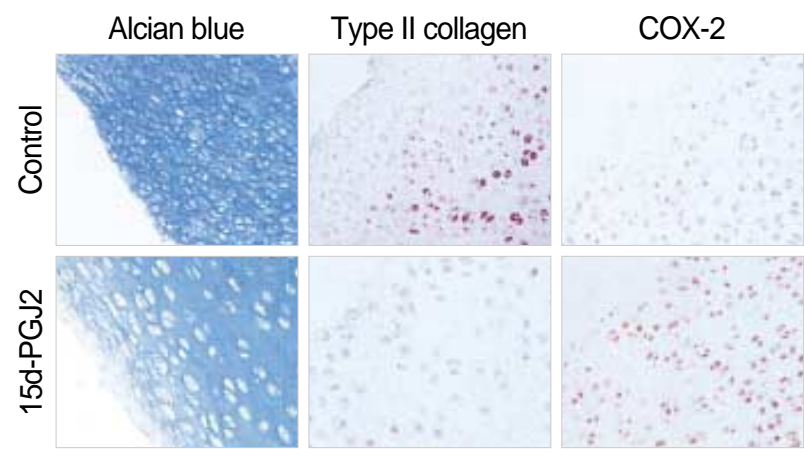

Fig. 3. 15d-PGJ2 causes dedifferentiation and COX-2 expression in articular chondrocytes. Cartilage explants were untreated or treated with $10 \mu \mathrm{M}$ 15d-PGJ2 for $24 \mathrm{hr}$. Type II collagen, COX-2, and proteoglycan were detected by immunohistochemical staining and Alcian blue staining, respectively. The data represent results of a typical experiment conducted at least four times.
(Fig. 3, middle panel) and sulfated proteoglycans (Fig. 3, left panel) as determined by immunohistochemical staining and Alcian blue staining, respectively. However, 15d-PGJ2 stimulated COX-2 expression (Fig. 3, right panel) as determined by immunohistochemical staining. These data indicate $15 \mathrm{~d}-$ PGJ2 also induces dedifferentiation and COX-2 expression in cartilage explants.

\section{5d-PGJ2 stimulates PPAR- $\gamma$-activation in articular chondrocytes}

To determine whether the PPAR- $\gamma$ expressed in the rabbit articular chondrocytes were transcriptionally active, a PPRE cloned upstream of luciferase (3xPPRE-TK-Luc/pGL3) was transiently transfected into articular chondrocyte cells, and the cells were then treated with 15d-PGJ2. As expected, expression of luciferase activity was significantly induced after 15d-PGJ2 treatment in a time- and dose-dependent manner (Fig. 4). The transfection efficiency was above $40 \%$ efficiency. These results indicate that 15d-PGJ2 increased PPAR- $\gamma$ transcription activity in articular chondrocytes.

\section{5d-PGJ2 regulates on dedifferentiation via PPAR- $\gamma$ - dependent pathway but not COX-2 expression}

Because 15d-PGJ2 in articular chondrocytes causes both dedifferentiation and COX-2 expression/PGE 2 production, we next examined whether PPAR- $\gamma$ activation is associated with dedifferentiation and/or COX-2 expression and $\mathrm{PGE}_{2}$ production. 15d-PGJ2-induced inhibition of type II collagen and SOX-9 expression was prevented by the addition of $10 \mu \mathrm{M}$ BADGE (bisphenol A diglycidyl ether, PPAR- $\gamma$ antagonist) (Fig. 5A). The 15d-PGJ2-induced inhibition of sulfated proteoglycan on primary culture chondrocytes was
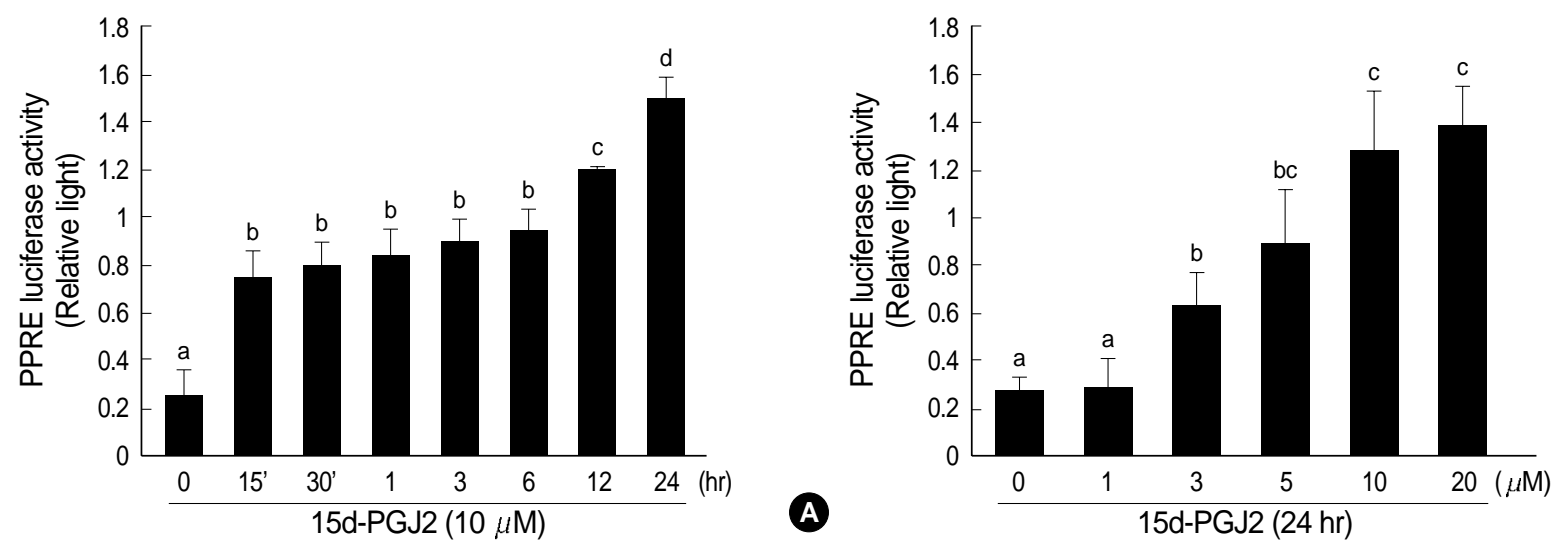

Fig. 4. 15d-PGJ2 stimulates PPAR- $\gamma$ transcriptional activity. Primary culture chondrocytes cells were co-transfected with reporter plasmids (3XPPRE-TK-Luc/pGL3) and RXR $a$ expression plasmids (RXR $\alpha / \mathrm{pSG} 5)$. pCMV $\beta$-galactosidase plasmid was used as an internal control for the transfection efficiency. Transfected cells were treated with 15d-PGJ2 (10 $\mu \mathrm{M})$ for various time periods $(\mathrm{A})$ or with the indicated concentrations of 15d-PGJ2 for $24 \mathrm{hr}(B)$. The cell extracts was assayed for luciferase activity and $\beta$-galactosidase activity. The data represent results of a typical experiment or mean values \pm S.D. from at least four independent experiments. The letters on the bar indicate significant differences among means $(\mathrm{n}=5)$ at $p=0.05$ using the Turkey's honestly significant difference method. 

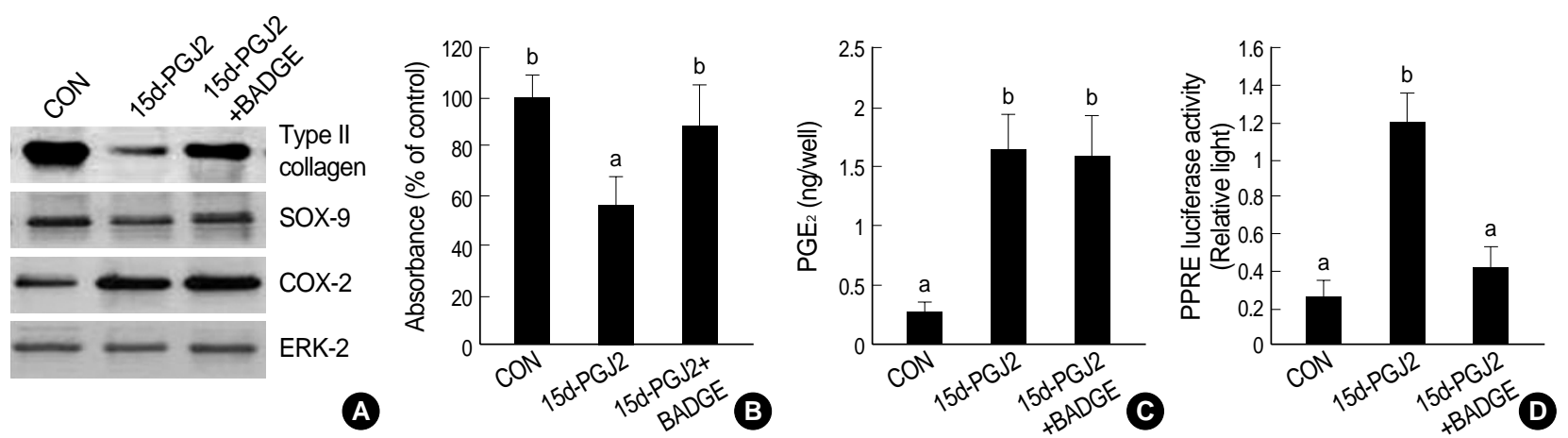

Fig. 5. Dedifferentiation and COX-2 expression mediated by 15d-PGJ2 regulates through PPAR- $\gamma$-dependent and -independent mechanism, respectively. Chondrocytes were treated with $10 \mu \mathrm{M}$ BADGE (PPAR- $\gamma$ antagonist) and then with $10 \mu \mathrm{M} 15 \mathrm{~d}-\mathrm{PGJ} 2$ for $24 \mathrm{hr}$. Type II collagen, SOX-9, COX-2, and ERK-2 were detected by immunoblot analysis (A). ERK-2 was used as loading controls. Accumulation of sulfated glycosaminoglycan was quantified by Alcian blue staining (B). PGE 2 was measured using an assay kit (C). (D) Primary culture chondrocytes were co-transfected with PPRE-containing reporter plasmid (3xPPRE-TK-Luc/pGL3) and RXR $\alpha$ expression plasmids (RXR $\alpha$ / pSG5) and pCMV $\beta$-gal plasmid, and the cells were treated with or without $10 \mu \mathrm{M}$ BADGE for 30 min prior to $10 \mu \mathrm{M} 15 \mathrm{~d}-\mathrm{PGJ} 2$ for $24 \mathrm{hr}$. The cell extracts were assayed for luciferase activity and $\beta$-galactosidase activity. The data represent results of a typical experiment (A) or mean values \pm S.D. (B, $C$ and $D$ ) from at least four independent experiments. The letters on the bar indicate significant differences among means $(\mathrm{n}=5)$ at $p=0.05$ using the Turkey's honestly significant difference method.

completely recovered by BADGE pretreatment (Fig. 5B). BADGE did not affect 15d-PGJ2-stimulated COX-2 expression (Fig. 5A) or $\mathrm{PGE}_{2}$ production (Fig. 5C). To elucidate the dedifferentiation mechanism, we examined PPAR- $\gamma$-response element (PPRE)-luciferase activity. As shown in Fig. 5D, 15d-PGJ2-enhanced PPAR- $\gamma$ activity was blocked by BADGE pretreatment. On the basis of these results, we suggest that 15d-PGJ2 regulates dedifferentiation via a PPAR$\gamma$-dependent pathway and COX-2 expression/PGE 2 production via a PPAR- $\gamma$-independent pathway.

\section{DISCUSSION}

Chondrocytes in normal articular cartilage are a unique cell type in that their differentiated phenotype is reversible. Chondrocyte phenotype is regulated by a balance of anabolic and catabolic molecular reactions that are involved in maintaining homeostasis of cartilage tissue (23). Differentiated chondrocytes lose their phenotype and transform into fibroblast-like cells upon exposure to soluble factors IL-1 $\beta$ (25), and nitric oxide (26) or during serial subculture in vitro (23). Such a destruction of homeostasis is believed to be involved in the pathophysiology of arthritis (27).

It was shown previously that $15 \mathrm{~d}-\mathrm{PGJ} 2$ has anti-inflammatory effects on both human chondrocytes (10) and rheumatoid synovial fibroblasts (28). However, the present study demonstrated the pro-inflammatory effect of $15 \mathrm{~d}-\mathrm{PGJ} 2$ in rabbit articular chondrocytes, suggesting a catabolic role of 15d-PGJ2 in cartilage. Thus far, controversy still remains regarding the role of $15 \mathrm{~d}-\mathrm{PGJ} 2$ in inflammatory responses (29). Indeed, the 15d-PGJ2 pathway has been shown to have anti- and pro-inflammatory effect (29), depending on experimental conditions and/or cell types.
PPAR $-\gamma$ is constitutively expressed in articular chondrocytes as shown by immunoblot in Fig. 2A. The presence of the expression of the PPAR $-\gamma$ in chondrocytes may provide a new insight in the understanding of the mechanisms which lead to the loss of cartilage homeostasis. Under inflammatory and pathologic conditions, however, PPAR- $\gamma$ plays an important role. Activation of this nuclear receptor by $15 \mathrm{~d}-\mathrm{PGJ} 2$ has been shown to be critical for the induction of rheumatoid arthritis and osteoarthritis. PPAR- $\gamma$ thus deserves consideration for clinical testing in degenerative cartilage diseases (30).

In this study, we demonstrated that an increase in PPAR- $\gamma$ activities is required for 15d-PGJ2-induced dedifferentiation of rabbit knee joint articular chondrocytes. However, 15d-PGJ2 treatment PPAR $-\gamma$ activity is not required for inflammatory responses (i.e. COX-2 expression/ $\mathrm{PGE}_{2}$ production). Thus, 15d-PGJ2-induced COX-2 expression/ $\mathrm{PGE}_{2}$ production is mediated by a PPAR- $\gamma$-independent pathway. In 1995, 15dPGJ2 was reported to be a high-affinity ligand for PPAR- $\gamma$, and diverse of its effects have been attributed to the activation of this nuclear receptor (11). However, there is increasing evidence that 15d-PGJ2 has diverse PPAR- $\gamma$-independent effects (31). Therefore, further studies are necessary to elucidate inflammatory responses-related different signaling mechanisms.

In summary, current knowledge indicates that PPAR- $\gamma$ plays a key role in the regulation of dedifferentiation in articular chondrocytes.

\section{REFERENCES}

1. Tontonoz P, Hu E, Spiegelman BM. Stimulation of adipogenesis in fibroblasts by PPAR gamma 2, a lipid-activated transcription factor. Cell 1994; 79: 1147-56.

2. Chawla A, Lazar M. Peroxisome proliferator and retinoid signaling 
pathways co-regulate preadipocyte phenotype and survival. Proc Natl Acad Sci USA 1994; 91: 1786-90.

3. Kliewer SA, Forman BM, Blumberg B, Ong ES, Borgmeyer U, Mangelsdorf DJ, Umesono K, Evans RM. Differential expression and activation of a family of murine peroxisome proliferator-activated receptors. Proc Natl Acad Sci USA 1994; 91: 7355-9.

4. Amri EZ, Bonino F, Ailhaud G, Abumrad NA, Grimaldi PA. Cloning of a protein that mediates transcriptional effects of fatty acids in preadipocytes. Homology to peroxisome proliferator-activated receptors. J Biol Chem 1995; 270: 2367-71.

5. Schmidt A, Endo N, Rutledge SJ, Vogel R, Shinar D, Rodan GA. Identification of a new member of the steroid hormone receptor superfamily that is activated by a peroxisome proliferator and fatty acids. Mol Endocrinol 1992; 6: 1634-41.

6. Chawla A, Schwarz EJ, Dimaculangan DD, Lazar MA. Peroxisome proliferator-activated receptor (PPAR) gamma: adipose-predominant expression and induction early in adipocyte differentiation. Endocrinology 1994; 135: 798-800.

7. Lin FT, Lane MD. CCAAT/enhancer binding protein alpha is sufficient to initiate the 3T3-L1 adipocyte differentiation program. Proc Natl Acad Sci USA 1994; 91: 8757-61.

8. Clark RB, Bishop-Bailey D, Estrada-Hernandez T, Hla T, Puddington L, Padula SJ. The nuclear receptor PPAR gamma and immunoregulation: PPAR gamma mediates inhibition of helper $T$ cell responses. J Immunol 2000; 164: 1364-71.

9. Bordji K, Grillasca JP, Gouze JN, Magdalou J, Schohn H, Keller JM, Bianchi A, Dauça M, Netter P, Terlain B. Evidence for the presence of peroxisome proliferator-activated receptor (PPAR) alpha and gamma and retinoid $Z$ receptor in cartilage. PPARgamma activation modulates the effects of interleukin-1beta on rat chondrocytes. J Biol Chem 2000; 275: 12243-50.

10. Fahmi H, Di Battista JA, Pelletier JP, Mineau F, Ranger P, MartelPelletier J. Peroxisome proliferator--activated receptor gamma activators inhibit interleukin-lbeta-induced nitric oxide and matrix metalloproteinase 13 production in human chondrocytes. J Arthritis Rheum 2001; 44: 595-607.

11. Kliewer SA, Umesono K, Noonan DJ, Heyman RA, Evans RM. Convergence of 9-cis retinoic acid and peroxisome proliferator signalling pathways through heterodimer formation of their receptors. Nature 1992; 358: 771-4.

12. Fajas L, Debril MB, Auwerx J. Peroxisome proliferators-activated receptor-gamma: from adipogenesis to carcinogenesis. J Mol Endocrinol 2001; 27: 1-9

13. Forman BM, Tontonoz P, Chen J, Brun RP, Spiegelman BM, Evans RM. 15-Deoxy-delta 12, 14-prostaglandin J2 is a ligand for the adipocyte determination factor PPAR gamma. Cell 1995; 83: 803-12.

14. Ricote M, Li AC, Willson TM, Kelly CJ, Glass CK. The peroxisome proliferator-activated receptor-gamma is a negative regulator of macrophage activation. Nature 1998; 391: 79-82.

15. Sarraf P, Mueller E, Jones D, King FJ, DeAngelo DJ, Partridge JB, Holden SA, Chen LB, Singer S, Fletcher C, Spiegelman BM. Differentiation and reversal of malignant changes in colon cancer through PPARgamma. Nat Med 1998; 4: 1046-52.

16. Tontonoz P, Singer S, Forman BM, Sarraf P, Fletcher JA, Fletcher
CD, Brun RP, Mueller E, Altiok S, Oppenheim H, Evans RM, Spiegelman BM. Terminal differentiation of human liposarcoma cells induced by ligands for peroxisome proliferator-activated receptor gamma and the retinoid $X$ receptor. Proc Natl Acad Sci USA 1997; 94: 237-41.

17. Mukherjee R, Davies PJ, Crombie DJ, Bischoff ED, Cesario RM, Jow L, Hamann LG, Boehm MF, Mondon CE, Nadzan AM, Paterniti JR Jr, Heyman RA. Sensitization of diabetic and obese mice to insulin by retinoid X receptor agonists. Nature 1997; 386: 407-10.

18. DeLise AM, Fischer L, Tuan RS. Cellular interactions and signaling in cartilage development. Osteoarthritis Cartilage 2000; 8: 309-34.

19. Sandell LJ, Aigner T. Articular cartilage and changes in arthritis. An introduction: cell biology of osteoarthritis. Arthritis Res 2001; 3: 107-13.

20. Arend WP, Dayer JM. Inhibition of the production and effects of interleukin-1 and tumor necrosis factor alpha in rheumatoid arthritis. Arthritis Rheum 1995; 38: 151-60.

21. Lotz M, Blanco FJ, von Kempis J, Dudler J, Maier R, Villiger PM, Geng Y. Cytokine regulation of chondrocyte functions. J Rheumatol Suppl 1995; 43: 104-8.

22. Dingle JT. Cartilage maintenance in osteoarthritis: interaction of cytokines, NSAID and prostaglandins in articular cartilage damage and repair. J Rheumatol Suppl 1991; 28: 30-7.

23. Yoon YM, Kim SJ, Oh CD, Ju JW, Song WK, Yoo YJ, Huh TL, Chun JS. Maintenance of differentiated phenotype of articular chondrocytes by protein kinase $C$ and extracellular signal-regulated protein kinase. J Biol Chem 2002; 277: 8412-20.

24. SAS Institute 1989. SAS/STAT User's Guide, Version 6. SAS Institute, Cary, NC, USA.

25. Goldring MB, Birkhead J, Sandell LJ, Kimura T, Krane SM. Interleukin 1 suppresses expression of cartilage-specific types II and IX collagens and increases types I and III collagens in human chondrocytes. J Clin Invest 1988; 82: 2026-37.

26. Kim SJ, Ju JW, Oh CD, Yoon YM, Song WK, Kim JH, Yoo YJ, Bang OS, Kang SS, Chun JS. ERK-1/2 and p38 kinase oppositely regulate nitric oxide-induced apoptosis of chondrocytes in association with p53, caspase-3, and differentiation status. J Biol Chem 2002; 277: 1332-9.

27. Gay S, Gay RE, Koopman WJ. Molecular and cellular mechanisms of joint destruction in rheumatoid arthritis: two cellular mechanisms explain joint destruction?. Ann Rheum Dis 1993; 52 (Suppl 1): 39-47.

28. Tsubouchi Y, Kawahito Y, Kohno M, Inoue K, Hla T, Sano H. Feedback control of the arachidonate cascade in rheumatoid synoviocytes by 15d-PGJ2. Biochem Biophys Res Commun 2001; 283: 750-5.

29. Shibata T, Kondo M, Osawa T, Shibata N, Kobayashi M, Uchida K. 15-deoxy-delta 12,14-prostaglandin J2. A prostaglandin D2 metabolite generated during inflammatory processes. J Biol Chem 2002; 277: 10459-66.

30. Shan ZZ, Masuko-Hongo K, Dai SM, Nakamura H, Kato T, Nishioka K. A potential role of 15-deoxy-delta-postaglandin J2 for induction of human articular chondrocyte apoptosis in arthritis. J Biol Chem 2004; 279: 37939-50.

31. Glass CK, Rosenfeld MG. The coregulator exchange in transcriptional functions of nuclear receptors. Genes Dev 2000; 14: 121-41. 